\title{
TRimetazidine as an Agent to affeCt clopidogrEl Response: The TRACER Study
}

\author{
Naveen Seecheran (D) - Victoria Seebalack • Rajeev Seecheran • \\ Aarti Maharaj · Brent Boodhai · Valmiki Seecheran · Sangeeta Persad • \\ Shastri Motilal · Antonio Tello-Montoliu · David Schneider
}

Received: May 5, 2019 / Published online: July 10, 2019

(C) The Author(s) 2019

\section{ABSTRACT}

Introduction: This prospective study aimed to determine whether trimetazidine (TMZ) alters the pharmacodynamic (PD) effects of clopidogrel.

Methods: Patients with stable coronary artery disease (SCAD) $(n=24)$ who were actively treated with dual antiplatelet therapy (DAPT) of aspirin $81 \mathrm{mg}$ daily and clopidogrel $75 \mathrm{mg}$ daily were recruited. Platelet function was measured with the VerifyNow P2Y12 assay (Accriva Diagnostics, San Diego, CA, USA) and assessed

Enhanced digital features To view enhanced digital features for this article go to https://doi.org/10.6084/ m9.figshare.8321108.

N. Seecheran $(\varangle) \cdot$ V. Seebalack $\cdot$ S. Motilal Department of Clinical Medical Sciences, The University of the West Indies, St. Augustine, Trinidad and Tobago

e-mail: Naveen.Seecheran@sta.uwi.edu

R. Seecheran · A. Maharaj · B. Boodhai .

V. Seecheran $\cdot$ S. Persad

Department of Medicine, North Central Regional

Health Authority, Port of Spain, Trinidad and

Tobago

A. Tello-Montoliu

Division of Cardiology, Universidad de Murcia,

Murcia, Spain

D. Schneider

Cardiovascular Research Institute of Vermont,

Colchester, VT, USA before the initiation of and after 14 days of treatment with TMZ. Results were compared using a paired $t$ test.

Results: Almost $80 \%$ of the study population were of South Asian descent and had diabetes mellitus (DM). P2Y12 reaction units (PRUs) were higher in patients on TMZ $(204 \pm 56$ compared with $174 \pm 71$ before TMZ, $p=0.005)$. The average increase in PRU score was 29 (95\% confidence interval 8.8-49.7). Before TMZ, the proportion of patients with high on-treatment platelet reactivity (PRU > 208 units) was $25 \%$, which increased to $42 \%$ for patients on TMZ.

Conclusion: Higher platelet reactivity was seen in patients on TMZ, suggesting that TMZ attenuated the PD effects of clopidogrel in this study of a predominantly South Asian diabetic subpopulation. Alternative therapies should be considered and further research is warranted.

Trial Registration: ClinicalTrials.gov number, NCT03603249.

Keywords: Clopidogrel; Platelet reactivity; Trimetazidine

\section{INTRODUCTION}

Clopidogrel has been a pivotal component of dual antiplatelet therapy (DAPT) in the therapeutic armamentarium for cardiovascular disease for over 20 years [1-3]. The 
pharmacodynamic (PD) effects of clopidogrel are variable and influenced by a plethora of genetic, drug-interaction, and clinical factors [3-6].

Mechanistically, activation of P2Y12 inhibits adenylate cyclase (AC), causing a decrease in cyclic adenosine monophosphate (cAMP) and phosphorylated vasodilator-stimulated phosphoprotein (VASP-P) levels, and activation of P2Y1 causes an increase in intracellular ionized calcium levels. These changes promote platelet aggregation by altering the ligand-binding properties of the glycoprotein IIb/IIIa (GP IIb/ IIIa) receptor. Therefore, inhibition of the P2Y12 receptor suppresses platelet activation [7].

Trimetazidine (TMZ) is a clinically effective antianginal agent without negative inotropic properties [8]. It is presently used throughout Europe and in other countries. It is cytoprotective, normalizing metabolic disturbances in ischemia via several mechanisms of action that have not been fully elucidated [9]. The major mechanism of action is its capacity to inhibit 2-oxidation of free fatty acids (FFAs) [10]. TMZ prevents a decrease in intracellular ATP levels, thereby ensuring the proper functioning of ionic pumps and transmembrane sodium-potassium flow while maintaining cellular homeostasis [11]. Several studies have assessed its clinical applicability in diabetes and ischemic cardiomyopathy to improve left ventricular and endothelial function, as an adjunctive agent in angina, in chronic heart failure with impaired myocardial energetics, and in post-percutaneous coronary intervention myocardial injury [12-16].

The 2013 European Society of Cardiology (ESC) guidelines consider TMZ to be a management option for stable coronary artery disease (SCAD); however, this is a class IIb recommendation [17]. Preliminary studies in patients with acute coronary syndromes (ACS) and hypertrophic cardiomyopathy (HCM) suggest a benefit, but efficacy is yet to be clearly established [18-25].

This study aimed to assess the effect of TMZ on the PD properties of clopidogrel in patients with stable angina.

\section{METHODS}

\section{Study Design and Patient Population}

The study complied with the Declaration of Helsinki, the International Conference on Harmonization, and good clinical practice, and was approved by both the Research Ethics Committee of the University of the West Indies, St. Augustine, Trinidad and the Public Health Observatory of the North Central Regional Health Authority $[26,27]$. All participants provided written informed consent to participate in a prospective, open-label study aimed at assessing the effect of TMZ on the PD of clopidogrel. Patients were enrolled between January 2019 and March 2019 and screened with a stratified permuted block randomization technique at the cardiology outpatient clinic at our institution (Eric Williams Medical Sciences Complex, Trinidad and Tobago) during assigned recruitment days (Fridays during routine working hours). The randomization sequence numbers were obtained from SPSS software (version 24.0; IBM SPSS Statistics, New York City, NY, USA). On average, 4-5 patients were enrolled every week for 5 weeks. They were considered eligible for the study if they were above 18 years of age, awaiting elective percutaneous coronary intervention (PCI) or coronary artery bypass grafting (CABG), and were on dual antiplatelet therapy (DAPT) for at least 4 weeks with an aspirin $81 \mathrm{mg}$ per day maintenance dose and a "brand name" clopidogrel $75 \mathrm{mg}$ per day maintenance dose (Plavix; Sanofi SA, Gentilly, France and Bristol-Myers Squibb, New York, USA). Exclusion criteria for this study included generic (i.e., not "brand name") clopidogrel, no recent acute coronary syndrome within 6 months, active bleeding, a prior cerebrovascular event, clinical instability after an index event, use of an oral anticoagulation agent (coumadin derivative or another anticoagulant therapy such as dabigatran, rivaroxaban, apixaban, or edoxaban), platelet count $<100 \times 10^{6} / 4 \mathrm{~L}$, hemoglobin $<10 \mathrm{~g} / \mathrm{dL}$, and serum creatinine $>2.5 \mathrm{mg} / \mathrm{dL}$. Patients were followed up for 28 days postprocedure to 
assess whether they experienced any adverse events.

\section{Blood Sampling and VerifyNow P2Y12 Testing}

Clopidogrel was held on the morning of their fasting scheduled visit (8:00 am to 9:00 am) so that their last maintenance dose of clopidogrel was given $18-24 \mathrm{~h}$ before baseline blood sampling. This was done to ensure the determination of trough levels of platelet reactivity. Blood samples were obtained at rest by antecubital puncture using a 21-gauge needle and placed into Vacuette (Greiner Bio-One North America, Monroe, NC, USA) blood collection tubes containing $3.8 \%$ trisodium citrate after discarding the first $5 \mathrm{ml}$ of blood to avoid artifactual platelet activation. Samples were processed by laboratory personnel blinded to ongoing study data. Platelet function assays included the VerifyNow P2Y12 (VN-P2Y12) assay (Accriva Diagnostics, San Diego, CA, USA). The assays were performed according to standard protocols, as previously described [28-30]. The VN-P2Y12 assay is a rapid whole-blood point-of-care device that reports results as P2Y12 reaction units (PRU). This assay mimics turbidimetric aggregation and utilizes disposable cartridges containing $20 \mathrm{mM}$ adenosine diphosphate (ADP) and $22 \mathrm{nM}$ prostaglandin E1 (PGE1). Aggregation testing using ADP as a sole agonist activates $\mathrm{P} 2 \mathrm{Y} 1$ and $\mathrm{P} 2 \mathrm{Y} 12$ purinergic signaling, while adding PGE1 increases the specificity of the test for P2Y12 signaling. A baseline value for platelet function is obtained in a separate channel of the cartridge in which iso-TRAP (thrombin receptor-activating peptide) is used as an agonist, enabling assessment of platelet inhibition without having to wean the patient off antiplatelet treatment. The VN-P2Y12 assay reports the results as $\mathrm{P} 2 \mathrm{Y} 12$ reaction units (PRU). A PRU $>208$ was considered HPR according to the last consensus [1]. The enrolled patients were then treated with TMZ at a dosage of $35 \mathrm{mg}$ twice daily for two weeks, with pill accountability assigned to the clinical research associate. After two weeks of TMZ, platelet reactivity was assessed a second time with the
VerifyNow assay using the aforementioned methodology (see Fig. 1).

\section{Patient Interview and Case Report Form}

Each patient's demographic data were recorded on a case report form (CRF). This contained the patient's medical and procedural history, including any active cardiovascular medications.

\section{Statistical Analysis}

The sample size was calculated as 24 patients based on a two-sided $p$-value of 0.05 , a power of $80 \%$, an estimated baseline prevalence of $25 \%$ of PRU $>208$, and an absolute delta of $10 \%$ (expected prevalence of $35 \%$ of PRU $>208$ ) [30]. Continuous variables were expressed as mean \pm standard deviation (SD), and categorical variables as frequencies and percentages.

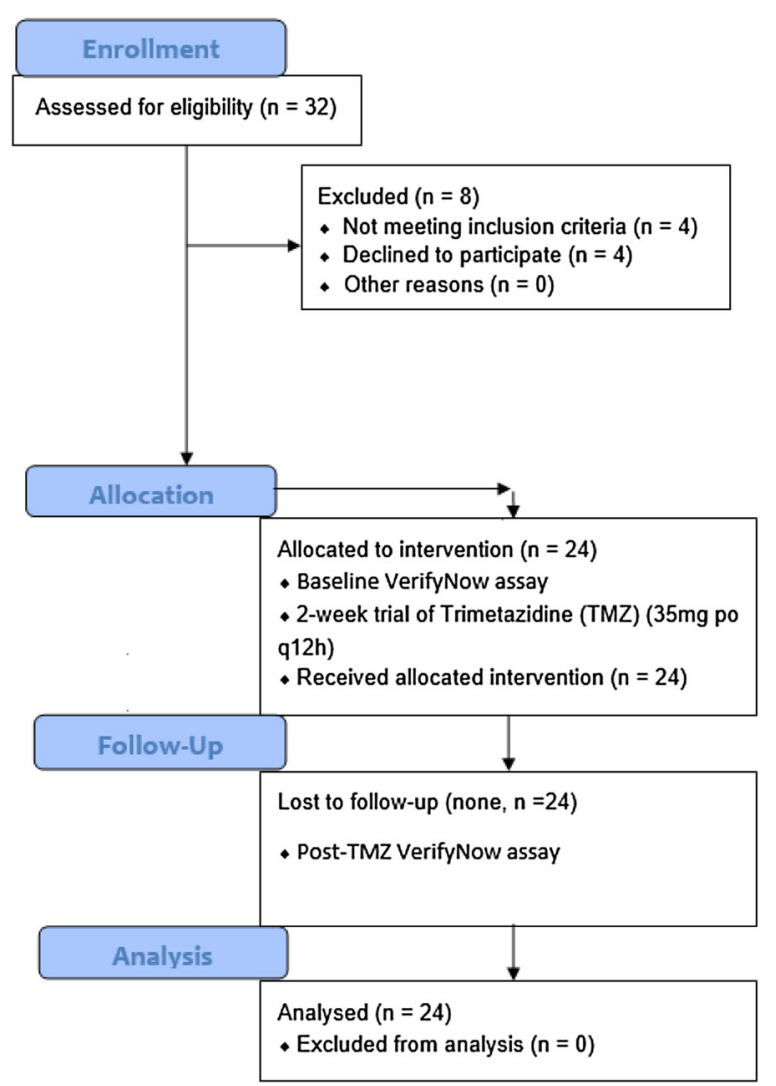

Fig. 1 Methodology outline 
The primary endpoint of PRU using a cutoff of $>208$ for high on-treatment platelet reactivity was used to create a dichotomous variable. No adjustments for multiple comparisons were made. Missing data were not imputed (none). A two-tailed $p$ value of 0.05 was considered to indicate a statistically significant difference in any of the analyses performed. Statistical analysis was performed using SPSS software (version 24.0; IBM SPSS Statistics, New York City, NY, USA).

\section{RESULTS}

A total of 24 individuals with stable coronary artery disease (SCAD) who were on dual antiplatelet therapy (DAPT) with aspirin and clopidogrel were enrolled in the study. Table 1 shows the demographics of the study participants. The mean age was nearly 60 years. Slightly more than $60 \%$ of the patients were males, with over three-quarters being South Asian (IndoTrinidadian) in ethnicity and the remainder being Caribbean Black (Afro-Caribbean), Caucasian, or interracial. The prevalence of diabetes was almost $80 \%$, with hypertension slightly greater than $80 \%$ and dyslipidemia roughly 90\%. Chronic kidney and lung diseases as well as cerebrovascular and peripheral artery diseases each accounted for less than one-fifth of all comorbidities. There was also a prevalence of at least $70 \%$ for the use of ACE inhibitors, betablockers, and high-intensity statins, with the prevalence of the latter surpassing $90 \%$. No patients had been previously treated with percutaneous coronary intervention (PCI), nor with coronary artery bypass grafting (CABG). One-quarter of the patients had high baseline on-treatment platelet reactivity with P2Y12 reaction units $>208$. There were no serious adverse events (SAEs).

P2Y12 reaction units (PRU) were higher in patients on TMZ $(204 \pm 56$ compared with $174 \pm 71$ before TMZ, $p=0.005)$. The average increase in PRU score was 29 (95\% confidence interval 49.7-8.8) (see Fig. 2). Before TMZ, the proportion of patients with high on-treatment platelet reactivity (PRU $>208$ units) was 25\%, which increased to $42 \%$ on TMZ $(p=0.219)$.

\section{DISCUSSION}

Mechanistically, the activation of P2Y12 inhibits adenylate cyclase (AC), causing a decrease in cyclic adenosine monophosphate (cAMP) and phosphorylation of vasodilator-stimulated phosphoprotein (VASP) that ultimately increases intracellular ionized calcium. These changes promote platelet activation, which includes cytoskeletal changes, release of granular products, and aggregation. ADP induces activation through interaction with both P2Y1 and P2Y12 receptors, and inhibition of the P2Y12 receptor suppresses platelet activation [7]. TMZ exerts its effects by preventing a decrease in intracellular adenosine triphosphate (ATP). This effect enhances ionic pump function and transmembrane sodium-potassium flow to maintain cellular homeostasis [31]. TMZ inhibits mitochondrial 3-ketoacyl-CoA thiolase, which increases glucose metabolism. In so doing, TMZ directs pyruvate into the mitochondria, leading to reduced proton and lactic acid production from the ischemic myocardium and more anaerobic cytosolic ATP production. High concentrations of ATP can act as an antagonist of the effects of adenosine diphosphate (ADP) at P2Y1 and P2Y12 receptors and inhibit ADP-induced platelet activation [32, 33]. In whole blood, ATP is metabolized to adenosine, which is an inhibitor of platelet activation [34-36]. It stimulates adenylate cyclase and increases the intracellular level of cAMP, which in turn inhibits calcium mobilization and other signal transduction pathways. While ATP can induce platelet activation [43], reduced activation is a consequence of very high concentrations of ATP because ATP can block interactions between $\mathrm{ADP}$ and the $\mathrm{P} 2 \mathrm{Y} 1$ or P2Y12 receptors [37].

Our study results suggest that treatment with $\mathrm{TMZ}$ attenuated the pharmacodynamic effects of clopidogrel in a predominantly South Asian diabetic subpopulation. Mechanisms that may explain this interaction include the promotion of activation through direct effects of the high levels of ATP induced by TMZ, or through the conversion of ATP to ADP by ecto-ATPases on blood cells (platelets or leukocytes). In addition, 
Table 1 Patient population

\begin{tabular}{|c|c|}
\hline Characteristics & Frequency (\%) \\
\hline Age & $\begin{array}{l}59.9 \text { (range } \\
47-73 \text { ) }\end{array}$ \\
\hline \multicolumn{2}{|l|}{ Gender } \\
\hline Female & $9(37.5)$ \\
\hline Male & $15(62.5)$ \\
\hline \multicolumn{2}{|l|}{ Ethnicity } \\
\hline South Asian & $19(79.2)$ \\
\hline Caribbean Black & $4(16.7)$ \\
\hline Caucasian & $1(4.2)$ \\
\hline Interracial & $0(0)$ \\
\hline \multicolumn{2}{|l|}{ Comorbidities } \\
\hline Diabetes mellitus & $19(79.2)$ \\
\hline Hypertension & $20(83.3)$ \\
\hline Dyslipidemia & $22(91.7)$ \\
\hline Chronic kidney disease & $1(4.2)$ \\
\hline Cerebrovascular events & $2(8.3)$ \\
\hline $\begin{array}{l}\text { Chronic obstructive pulmonary } \\
\text { disease }\end{array}$ & $0(0)$ \\
\hline Peripheral artery disease & $3(12.5)$ \\
\hline \multicolumn{2}{|l|}{ Cardiovascular medications } \\
\hline Aspirin & $24(100)$ \\
\hline Clopidogrel & $24(100)$ \\
\hline ACE inhibitor/angiotensin receptor & $17(70.8)$ \\
\hline \multicolumn{2}{|l|}{ Blocker } \\
\hline Beta-blocker & $20(83.3)$ \\
\hline Statin & $23(95.8)$ \\
\hline Calcium channel blocker & $6(25)$ \\
\hline Nitrates & $4(16.7)$ \\
\hline $\begin{array}{l}\text { Mineralocorticoid receptor } \\
\text { antagonist }\end{array}$ & $0(0)$ \\
\hline Ivabradine & $2(8.3)$ \\
\hline Sacubitril & $0(0)$ \\
\hline Cardiovascular procedures & \\
\hline
\end{tabular}

Table 1 continued

\begin{tabular}{ll}
\hline Characteristics & Frequency (\%) \\
\hline Percutaneous coronary intervention & $0(0)$ \\
Coronary artery bypass grafting & $0(0)$ \\
P2Y12 reaction units & \\
$>208$ & $6(25)$ \\
$<208$ & $18(75)$ \\
\hline
\end{tabular}

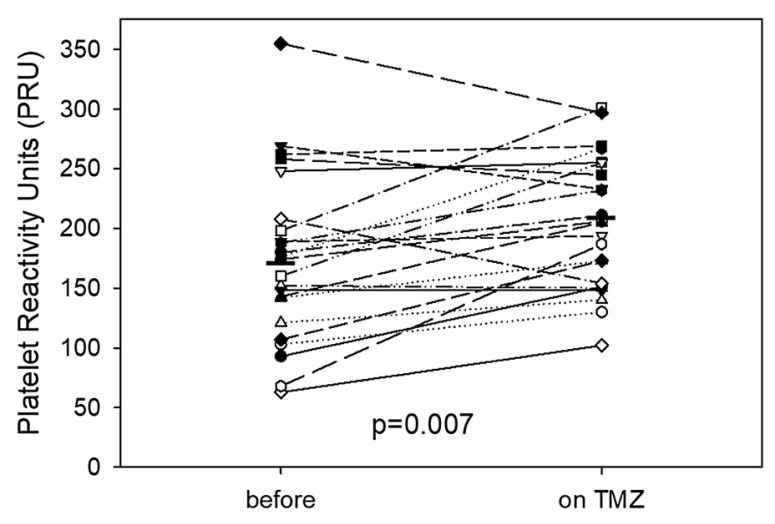

Fig. 2 Individual patient baseline P2Y12 reaction units (PRU) compared to PRU score on TMZ

the effect of TMZ on cAMP inside platelets may contribute to the observed effects [44]. Previous studies have not demonstrated that TMZ promotes platelet activation [38-40]. TMZ may interfere with the binding of the active metabolite of clopidogrel to the P2Y12 receptor.

As TMZ appears to mitigate clopidogrel response, further large-scale studies are recommended to examine these findings, and alternative therapies should be considered [41-43].

\section{Study Limitations}

Although the study was adequately powered, there was a notably high prevalence of patients with diabetes mellitus-approximately $80 \%$, as compared to $46 \%$ in a previous Trinidadian study assessing cardiovascular medication adherence [44]. Diabetes is associated with increased platelet reactivity, and involves hyperglycemia, hyperlipidemia, insulin 
resistance, absolute insulin deficiency, oxidative stress, inflammation, and endothelial dysfunction [4]. Almost four-fifths of the patient population was South Asian; this ethnicity has also been implicated in high on-treatment platelet reactivity. In a recent study by Seecheran et al., there was a significant association between HPR (P2Y12 reaction units $>208$ ) and South Asian (Indo-Trinidadian) ethnicity (OR 5.4; 95\% CI 1.18 to $24.66, p=0.029$ ) [30]. These two issues suggest a selection bias, as all patients were screened at the outpatient cardiology clinic and may therefore have been at increased risk for diabetes (which Trinidadian South Asians tend to develop), although robust attempts were made to reduce this by randomizing enrollment and applying stringent selection criteria. All patients bar one were on statin therapy, which can affect platelet reactivity, with recent studies alluding to an enhanced pharmacodynamic response to clopidogrel $[45,46]$. This is in stark contrast to the typical statin adherence of almost two-thirds, as illustrated by the aforementioned local study. Our study results are reflective of patients who are predominantly South Asian and have diabetes, and thus cannot be extrapolated to the general population.

\section{CONCLUSIONS}

Treatment with trimetazidine was associated with increased platelet reactivity among patients with stable coronary artery disease who were treated with clopidogrel. Alternative therapies should be considered, and further research is warranted.

\section{ACKNOWLEDGEMENTS}

We thank the participants in the study.

Funding. This study was sponsored by the Campus Research and Publication Fund (CRP.4MAR16.38) from the University of the West Indies, St. Augustine, which provided TTD 50,000. The article processing charges were funded by the authors. All authors had full access to all of the data in this study and take complete responsibility for the integrity of the data and the accuracy of the data analysis.

Authorship. All named authors meet the International Committee of Medical Journal Editors (ICMJE) criteria for authorship for this article, take responsibility for the integrity of the work as a whole, and have given their approval for this version to be published.

Author Contributions. Naveen Seecheran, Antonio Tello-Montoliu, and David Schneider conceived the study. Victoria Seebalack, Rajeev Seecheran, Aarti Maharaj, Brent Boodhai, Valmiki Seecheran, and Sangeeta Persad initiated the study design and Naveen Seecheran and Shastri Motilal helped with its implementation. Naveen Seecheran is the grant holder. Shastri Motilal and David Schneider provided statistical expertise in clinical trial design, and David Schneider conducted the primary statistical analysis. All authors helped to refine the study protocol and approved the final manuscript.

Disclosures. The authors Naveen Seecheran, Victoria Seebalack, Rajeev Seecheran, Aarti Maharaj, Brent Boodhai, Valmiki Seecheran, Sangeeta Persad, Shastri Motilal, Antonio TelloMontoliu, and David Schneider have nothing to disclose.

Compliance with Ethics Guidelines. The study complied with the Declaration of Helsinki, the International Conference on Harmonization, and good clinical practice, and was approved by both the Research Ethics Committee of the University of the West Indies, St. Augustine, Trinidad and the Public Health Observatory of the North Central Regional Health Authority. All participants provided written informed consent to participate in a prospective, open-label study aimed at assessing the effect of TMZ on the PD of clopidogrel.

Data Availability. All available data can be obtained by contacting the corresponding author. ClinicalTrials.gov number for TRACER: NCT03603249. All materials, data, code, and 
associated protocols will be made promptly available to the editor and to readers upon request. There are no restrictions on the availability of materials.

Open Access. This article is distributed under the terms of the Creative Commons Attribution-NonCommercial 4.0 International License (http://creativecommons.org/licenses/ by-nc/4.0/), which permits any noncommercial use, distribution, and reproduction in any medium, provided you give appropriate credit to the original author(s) and the source, provide a link to the Creative Commons license, and indicate if changes were made.

\section{REFERENCES}

1. Tantry US, Bonello L, Aradi D, Price MJ, Jeong Y-H, Angiolillo DJ, et al. Consensus and update on the definition of on-treatment platelet reactivity to adenosine diphosphate associated with ischemia and bleeding. J Am Coll Cardiol. 2013;62(24):2261-73. https://doi.org/10.1016/j. jacc.2013.07.101.

2. Mega JL, Close SL, Wiviott SD, Shen L, Hockett RD, Brandt JT, et al. Cytochrome p-450 polymorphisms and response to clopidogrel. $\mathrm{N}$ Engl J Med. 2009;360(4):354-62. NEJMoa0809171.

3. Matetzky S, Shenkman B, Guetta V. Clopidogrel resistance is associated with increased risk of recurrent atherothrombotic events in patients with acute myocardial infarction. ACC Curr J Rev. 2004;13(9):9. https://doi.org/10.1016/j.accreview. 2004.08.004.

4. Schneider DJ. Factors contributing to increased platelet reactivity in people with diabetes. Diabetes Care. 2009;32(4):525-7. https://doi.org/10.2337/ dc08-1865.

5. Franchi F, Angiolillo DJ. Novel antiplatelet agents in acute coronary syndrome. Nat Rev Cardiol. 2015;12:30-47. https://doi.org/10.1038/nrcardio. 2014.156.

6. Nguyen TA, Diodati JG, Pharand C. Resistance to clopidogrel: a review of the evidence. J Am Coll Cardiol. 2005;45(8):1157-64. https://doi.org/10. 1016/j.jacc.2005.01.034.
7. Angiolillo DJ, Ueno M, Goto S. Basic principles of platelet biology and clinical implications. Circ J. 2010;74(4):597-607. https://www.ncbi.nlm.nih. gov/pubmed/20197627.

8. Kantor PF, Lucien A, Kozak R, Lopaschuk GD. The antianginal drug trimetazidine shifts cardiac energy metabolism from fatty acid oxidation to glucose oxidation by inhibiting mitochondrial long-chain 3-ketoacyl coenzyme A thiolase. Circ Res. 2000;86(5):580-8. https://www.ncbi.nlm.nih.gov/ pubmed/10720420.

9. Chrusciel P, Rysz J, Banach M. Defining the role of trimetazidine in the treatment of cardiovascular disorders: some insights on its role in heart failure and peripheral artery disease. Drugs. 2014;74:971-80. http://dx.doi.org/10.1007/s40265014-0233-5.

10. Cross HR. Trimetazidine for stable angina pectoris. Expert Opin Pharmacother. 2001;2:857-75. http:// dx.doi.org/10.1517/14656566.2.5.857.

11. Stanley WC, Marzilli M. Metabolic therapy in the treatment of ischaemic heart disease: the pharmacology of trimetazidine. Fundamental Clin Pharmacol. 2003;17:133-45. https://doi.org/10.1046/j. 1472-8206.2003.00154.x.

12. Fragasso G, Piatti PM, Monti L, Palloshi A, Setola E, Puccetti P, et al. Short- and long-term beneficial effects of trimetazidine in patients with diabetes and ischemic cardiomyopathy. Am Heart J. 2003;146:854. https://doi.org/10.1016/s00028703(03)00415-0.

13. Detry JM, Sellier P, Pennaforte S, Cokkinos D, Dargie $\mathrm{H}$, Mathes $\mathrm{P}$. Trimetazidine: a new concept in the treatment of angina. Comparison with propranolol in patients with stable angina. Trimetazidine European Multicenter Study Group. Br J Clin Pharmacol. 1994;37(3):279-88. https://www.ncbi. nlm.nih.gov/pubmed/8198938.

14. Lam CSP, Voors AA, de Boer RA, Solomon SD, van Veldhuisen DJ. Heart failure with preserved ejection fraction: from mechanisms to therapies. Eur Heart J. 2018;39(30):2780-92. https://doi.org/10.1093/ eurheartj/ehy301.

15. Fragasso G, Palloshi A, Puccetti P, Silipigni C, Rossodivita A, Pala M, et al. A randomized clinical trial of trimetazidine, a partial free fatty acid oxidation inhibitor, in patients with heart failure. J Am Coll Cardiol. 2006;48(5):992-8. https://doi.org/10.1016/ j.jacc.2006.03.060.

16. Ambesh P, Kazmi DH, Kapoor A, Sinha A, Khanna $\mathrm{R}$, Kumar S, et al. Role of metabolic manipulator trimetazidine in limiting percutaneous coronary intervention associated myocardial injury. J Am 
College Cardiol. 2018;71:A1438. https://doi.org/10. 1016/s0735-1097(18)31979-X.

17. Task Force Members, Montalescot G, Sechtem U, Achenbach S, Andreotti F, Arden C, et al. ESC guidelines on the management of stable coronary artery disease. Eur Heart J. 2013;34:2949-3003. http://dx.doi.org/10.1093/eurheartj/eht296.

18. McMurray JJ, Adamopoulos S, Anker SD, Auricchio A, Böhm M, Dickstein K, et al. ESC Guidelines for the diagnosis and treatment of acute and chronic heart failure 2012: The Task Force for the Diagnosis and Treatment of Acute and Chronic Heart Failure 2012 of the European Society of Cardiology. Developed in collaboration with the Heart Failure Association (HFA) of the ESC. Eur Heart J. 2012;33:1787-847. https://doi.org/10.1093/ eurheartj/ehs104.

19. Hamm CW, Bassand J-P, Agewall S, Bax J, Boersma $\mathrm{E}$, Bueno $\mathrm{H}$, et al. ESC guidelines for the management of acute coronary syndromes in patients presenting without persistent ST-segment elevation. Rev Esp Cardiol (Engl Ed). 2012;65:173. http://dx. doi.org/10.1016/j.rec.2011.11.006.

20. McClellan KJ, Plosker GL. Trimetazidine. Drugs. 1999;58:143-57. 00003495-199958010-00016.

21. Marzilli M. Trimetazidine: a metabolic agent for the treatment of stable angina. Eur Heart J Suppl. 2001;3:O12. https://doi.org/10.1016/s1520765x(01)90149-x.

22. Ciapponi A, Pizarro R, Harrison J. Trimetazidine for stable angina. Cochrane Database Syst Rev. 2005. http://dx.doi.org/10.1002/14651858.cd003614. pub2.

23. Szwed H. Combination treatment in stable effort angina using trimetazidine and metoprolol. Results of a randomized, double-blind, multicentre study (TRIMPOL II). Eur Heart J. 2001;22:2267-74. http:// dx.doi.org/10.1053/euhj.2001.2896.

24. Chazov EI, Lepakchin VK, Zharova EA, Fitilev SB, Levin AM, Rumiantzeva EG, et al. Trimetazidine in angina combination therapy-the TACT study: trimetazidine versus conventional treatment in patients with stable angina pectoris in a randomized, placebo-controlled, multicenter study. Am J Therapeut. 2005;12:35-42. http://dx.doi.org/10. 1097/00045391-200501000-00006.

25. Coats CJ, Pavlou M, Watkinson OT, Protonotarios A, Moss L, Hyland R, et al. Effect of trimetazidine dihydrochloride therapy on exercise capacity in patients with nonobstructive hypertrophic cardiomyopathy: a randomized clinical trial. JAMA
Cardiol. 2019. https://doi.org/10.1001/jamacardio. 2018.4847.

26. Christie B. Doctors revise Declaration of Helsinki. BMJ. 2000;321(7266):913. https://doi.org/10.1136/ bmj.321.7266.913.

27. D'Agostino RB, Sullivan L, Massaro J, editors. International Conference on Harmonisation of Technical Requirements for Registration of Pharmaceuticals for Human Use (ICH). In: Wiley Encyclopedia of Clinical Trials. Hoboken, NJ: Wiley; 2008. http://dx.doi.org/10.1002/9780471462422. eoct 457 .

28. Angiolillo DJ, Badimon JJ, Saucedo JF, Frelinger AL, Michelson AD, Jakubowski JA, et al. A pharmacodynamic comparison of prasugrel vs high-dose clopidogrel in patients with type 2 diabetes mellitus and coronary artery disease: results of the Optimizing anti-Platelet Therapy In diabetes MellitUS (OPTIMUS)-3 Trial. Eur Heart J. 2011;32(7):838-46. https://doi.org/10.1093/eurheartj/ehq494.

29. Angiolillo DJ, Saucedo JF, Deraad R, Frelinger AL, Gurbel PA, Costigan TM, et al. Increased platelet inhibition after switching from maintenance clopidogrel to prasugrel in patients with acute coronary syndromes: results of the SWAP (SWitching Anti Platelet) study. J Am Coll Cardiol. 2010;56(13):1017-23. https://doi.org/10.1016/j. jacc.2010.02.072.

30. Seecheran NA, Maharaj A, Boodhai B, Seecheran R, Seecheran V, Persad S, et al. Prevalence of clOpidogrel "resIstaNce" in a selected population of patients undergoing elective percutaneous coronary intervention at a tertiary cardiovascular centre in Trinidad: the POINT pilot study. Open Heart. 2019;6(1):e000841. https://doi.org/10.1136/ openhrt-2018-000841.

31. Stanley WC, Marzilli M. Metabolic therapy in the treatment of ischaemic heart disease: the pharmacology of trimetazidine. Fundamental Clin Pharmacol. 2003;17:133-45. https://doi.org/10.1046/j. 1472-8206.2003.00154.x.

32. Hourani SMO. Discovery and recognition of purine receptor subtypes on platelets. Drug Dev Res. 2001;52:140-9. https://doi.org/10.1002/ddr.1108.

33. Stafford NP, Pink AE, White AE, Glenn JR, Heptinstall S. Mechanisms involved in adenosine triphosphate-induced platelet aggregation in whole blood. Arterioscler Thromb Vasc Biol. 2003;23(10):1928-33. https://doi.org/10.1161/01. ATV.0000089330.88461.D6.

34. Coade SB, Pearson JD. Metabolism of adenine nucleotides in human blood. Circ Res. 
1989;65(3):531-7. https://www.ncbi.nlm.nih.gov/ pubmed/2548757.

35. Birk AV, Johan Broekman M, Gladek EM, Robertson HD, Drosopoulos JHF, Marcus AJ, et al. Role of extracellular ATP metabolism in regulation of platelet reactivity. J Lab Clin Med. 2002;140:166-75. https://doi.org/10.1067/mlc.2002.126719.

36. Kroll MH, Schafer AI. Biochemical mechanisms of platelet activation. Blood. 1989;74(4):1181-95. https://www.ncbi.nlm.nih.gov/pubmed/2669994.

37. Nicholas RA. Identification of the P2Y(12) receptor: a novel member of the P2Y family of receptors activated by extracellular nucleotides. Mol Pharmacol. 2001;60(3):416-20. https://www.ncbi.nlm. nih.gov/pubmed/11502870.

38. Willoughby SR, Chirkov YY, Kennedy JA, Murphy GA, Chirkova LP, Horowitz JD. Inhibition of longchain fatty acid metabolism does not affect platelet aggregation responses. Eur J Pharmacol. 1998;356:207-13. https://doi.org/10.1016/s00142999(98)00527-5.

39. Astarie-Dequeker C, Joulin Y, Devynck MA. Inhibitory effect of trimetazidine on thrombin-induced aggregation and calcium entry into human platelets. J Cardiovasc Pharmacol. 1994;23(3):401-7. https://www.ncbi.nlm.nih.gov/pubmed/7515983.

40. Devynck MA, Le Quan Sang KH, Joulin Y, Mazeaud M. Acute membrane effects of trimetazidine in human platelets. Eur J Pharmacol. 1993;245(2):105-10. https://www.ncbi.nlm.nih. gov/pubmed/8387923.

41. Mega JL, Braunwald E, Wiviott SD, Bassand J-P, Bhatt DL, Bode $\mathrm{C}$, et al. Rivaroxaban in patients with a recent acute coronary syndrome. N Engl J
Med. 2012;366(1):9-19. https://doi.org/10.1056/ NEJMoa1112277.

42. Ohman EM, Roe MT, Steg PG, James SK, Povsic TJ, White J, et al. Clinically significant bleeding with low-dose rivaroxaban versus aspirin, in addition to P2Y12 inhibition, in acute coronary syndromes (GEMINI-ACS-1): a double-blind, multicentre, randomised trial. Lancet. 2017;389(10081):1799-808. https://doi.org/10.1016/S0140-6736(17)30751-1.

43. Gibson CM, Michael Gibson C, Mehran R, Bode C, Halperin J, Verheugt FW, et al. Prevention of bleeding in patients with atrial fibrillation undergoing PCI. N Engl J Med. 2016;375(25):2423-34. https://doi.org/10.1056/nejmoa1611594.

44. Seecheran N, Nandlal N, Nankissoon S, Nancoo C, Nelson C, Nkemakolam A, et al. A Trinidadian cardiovascular medication adherence survey: the ADHERE TNT study. Int J Commun Med Publ Health. 2017;4:3601. https://doi.org/10.18203/ 2394-6040.ijcmph20174218.

45. Toso A, De Servi S, Leoncini M, Angiolillo DJ, Calabrò P, Piscione F, et al. Effects of statin therapy on platelet reactivity after percutaneous coronary revascularization in patients with acute coronary syndrome. J Thromb Thrombolysis. 2017;44(3):355-61. https://doi.org/10.1007/ s11239-017-1541-x.

46. Godino C, Pavon AG, Mangieri A, Salerno A, Cera $\mathrm{M}$, Monello A, et al. Platelet reactivity in response to loading dose of atorvastatin or rosuvastatin in patients with stable coronary disease before percutaneous coronary intervention: the STATIPLAT randomized study. Clin Cardiol. 2017;40(8):605-11. https://doi.org/10.1002/clc. 22709 . 